\title{
'n Leksikografiese datatrekkingstruktuur vir aanlyn woordeboeke
}

Rufus H. Gouws, Departement Afrikaans en Nederlands, Universiteit Stellenbosch, Stellenbosch, Suid-Afrika (rhg@sun.ac.za)

Opsomming: Op die gebied van die leksikografie het die oorgang vanaf gedrukte na aanlyn woordeboeke ' $n$ ingrypende invloed op talle aspekte van sowel die leksikografieteorie as die leksikografiepraktyk. In die voortgesette ontwikkeling van die leksikografieteorie moet hierdie invloed verwoord word sodat daar riglyne gebied kan word vir die optimale benutting van die vooruitspruitende aanpassings in die leksikografiepraktyk. Woordeboekstrukture moet opnuut ondersoek word om vas te stel watter strukture in die nuwe medium behou kan word, watter strukture aan aanpassings onderhewig is en watter nuwe strukture na vore tree.

In hierdie artikel is die fokus op aanpassings in leksikografiese strukture. Daar word verwys na strukture waarvoor aanpassings reeds in die metaleksikografie bespreek is. Die hoofklem is op verskillende vorme van die dataverspreidingstruktuur in aanlyn woordeboeke. Voorsiening word gemaak vir 'n omvattende dataverspreidingstruktuur wat in woordeboekportale gebruik kan word en die gebruiker toegang tot woordeboekeksterne bronne gee. Die behoefte aan groter vryheid van die gebruiker om data te kies wat benodig word, lei tot voorstelle vir 'n nuwe struktuur, naamlik die datatrekkingstruktuur. Met behulp van hierdie struktuur kan gebruikers regstreeks vanuit ' $n$ bepaalde posisie in 'n aanlyn woordeboek toegang kry tot die internet as leksikografiese korpus om aan die data daar die inligting te onttrek wat in 'n bepaalde gebruiksituasie verlang word. Die datatrekkingstruktuur bevestig die status van woordeboeke as geïntegreerde inligtingsinstrumente en plaas hulle binne die bestek van ' $n$ oorkoepelende datastruktuur.

Sleutelwoorde: AANLYN WOORDEBOEK, DATASTRUKTUUR, DATATREKKINGSTRUKTUUR, DATAVERSPREIDINGSTRUKTUUR, EENVOUDIGE DATAVERSPREIDINGSTRUKTUUR, LEKSIKOGRAFIESE STRUKTURE, OMVATTENDE DATAVERSPREIDINGSTRUKTUUR, OORKOEPELENDE DATAVERSPREIDINGSTRUKTUUR, STOOTMEDIUM, TREKMEDIUM, UITGEBREIDE DATAVERSPREIDINGSTRUKTUUR, WOORDEBOEKPORTAAL, WOORDEBOEKPORTAALSTRUKTUUR

\footnotetext{
Abstract: A Lexicographic Data Pulling Structure for Online Dictionaries. In the field of lexicography the transition from printed to online dictionaries has had a significant influence on numerous aspects of both lexicographic theory and the lexicographic practice. In the continued development of lexicographic theory this influence has to be formulated in order to present guidelines for the optimal application of the resulting adaptations in the lexicographic practice. Dictionary structures should be investigated to determine which structures can be maintained in the new medium, which structures need to be adapted and which new structures are coming to the fore.
} 
The focus in this article is on adaptations in lexicographic structures. Reference is made to structures of which the adaptations have already been discussed in metalexicography. The main emphasis is on different types of data distribution structures in online dictionaries. Provision is made for a comprehensive data distribution structure that can be employed in dictionary portals to give the user access to dictionary-external sources. The need of users for more freedom to select their required data, leads to proposals for a new structure, namely the data pulling structure. By employing this structure users can access the internet as lexicographic corpus from any point in an online dictionary to retrieve from the data there the information they require in a specific situation of use. The data pulling structure confirms the status of dictionaries as integrated information instruments and puts them within the scope of an over-arching data structure.

Keywords: COMPREHENSIVE DATA DISTRIBUTION STRUCTURE, DATA DISTRIBUTION STRUCTURE, DATA PULLING STRUCTURE, DATA STRUCTURE, DICTIONARY PORTAL, DICTIONARY PORTAL STRUCTURE, EXTENDED DATA DISTRIBUTION STRUCTURE, LEXICOGRAPHIC STRUCTURES, ONLINE DICTIONARY, OVER-ARCHING DATA DISTRIBUTION STRUCTURE, PULL MEDIUM, PUSH MEDIUM, SINGLE DATA DISTRIBUTION STRUCTURE

\section{Inleiding}

'n Oorsig oor die ontwikkeling van die leksikografiepraktyk lewer bewys van 'n verskeidenheid belangwekkende oorgange, byvoorbeeld die oorgang van kleitablette na perkamentrolle en na papier, die oorgang van ' $n$ tematiese ordening van woordeboeke na 'n alfabetiese ordening, die oorgang na die drukpers en later na die rekenaar as instrumente in die samestelling van woordeboeke en die koms van elektroniese korpora. Die ingrypendste oorgang, sonder twyfel, was die oorgang van die gedrukte na die elektroniese medium en meer spesifiek die leksikografiese toetrede tot die aanlyn omgewing. Dit was nie net 'n oorgang wat die medium waarin die leksikografiese werk gedoen word, betref nie, maar veel meer as dit. Hierdie oorgang was 'n paradigmaskuif wat die tipe leksikografiese werktuie, die inhoud van woordeboeke, die wisselwerking met ander naslaanbronne en die aard en omvang van die verpakking van data verander het (vergelyk Rundell 2012: 72)

Aanlyn woordeboeke gee tans nie altyd blyke van die nodige metaleksikografiese onderbou nie. Dit is nie net die gevolg daarvan dat die samestelling dikwels deur mense met die nodige tegniese kennis maar gebrekkige leksikografiese kennis gedoen word nie, maar ook omdat metaleksikograwe nog nie voldoende ondersteuning aan die nuwe leksikografiepraktyk gebied het nie. Te veel aspekte van die teoretiese leksikografie is nog slegs op gedrukte woordeboeke gerig. In die voortgaande leksikografiese gesprek is dit dringend noodsaaklik dat die moontlikhede wat die aanlyn omgewing aan die leksikografie bied uitvoerig ter sprake moet kom sodat die nodige aanpassings gedoen kan word ter daarstelling van die formulering van 'n algemene leksikografieteorie wat nie medium-spesifiek is nie. Hierdie aanpassing by die aanlyn omgewing 
geld alle aspekte van die leksikografie.

Leksikografiese strukture as een onderafdeling in die formulering van ' $n$ algemene leksikografieteorie maar ook in die beplanning en samestelling van woordeboeke, word in hierdie artikel aan die orde gestel. Daar word kortliks verwys na aanpassings in strukture soos die makro-, artikel-, adresserings- en toegangstruktuur. Daarna word meer aandag gegee aan die dataverspreidingstruktuur en voorstelle word gemaak vir die erkenning van 'n nuwe leksikografiese struktuur, naamlik die datatrekkingstruktuur. Die siening van 'n woordeboek as 'n houer van kennis, sien McArthur (1986), en as 'n draer van tekssoorte, sien Wiegand (1996) word ook kortliks krities onder die loep geneem.

Volgens Wiegand (1989: 251) is leksikografie 'n praktyk wat gerig is op die produksie van woordeboeke sodat 'n verdere praktyk, naamlik die kulturele praktyk van woordeboekgebruik, 'n aanvang kan neem. Woordeboeke is praktiese gebruiksinstrumente en hierdie funksie word nie bepaal deur die medium van 'n woordeboek nie. Gevolglik moet die gesprek oor aanlyn leksikografie steeds die belang van die gebruiker in ag neem. In die hieropvolgende paragraaf kom dit kortliks ter sprake.

\section{Die gebruikersperspektief}

Die gebruikersperspektief met sy fokus op die vasstelling van 'n spesifieke teikengebruiker en die leksikografiese behoeftes en naslaanvaardighede van daardie gebruiker staan reeds lank sentraal in die metaleksikografiese gesprek, vergelyk onder meer Hartmann $(1989 ; 2001)$. As deel van die reaksie op die behoeftes van die teikengebruiker moet daar ook duidelikheid wees oor die funksie wat die betrokke woordeboek moet hê om die spesifieke behoeftes van die gebruiker te kan bevredig.

Ter sake in sowel gedrukte as aanlyn woordeboeke is die gebruikersperspektief. Ook in aanlyn woordeboeke mag die gebruiker nie langer die bekende onbekende (Wiegand 1977: 59) wees nie. Die behoeftes maar ook naslaanvaardighede van duidelik gespesifiseerde gebruikers moet bepalend wees in die keuse en aanbieding van data in woordeboeke. Ook leksikografiese strukture moet hierdie gebruikers ter wille wees. Daar moet in die teorie-ontwikkeling deurgaans rekening gehou word met ' $n$ veranderende en veranderde gebruikersgroep.

Een van die reuse-uitdagings van die hedendaagse leksikografie is om woordeboeke te produseer wat steeds relevant is en wat gebruik word. In die formulering van die leksikografieteorie asook in die beplanning van nuwe woordeboeke moet vernuwende denke daarop gerig wees om gebruikers en potensiële gebruikers daarvan bewus te hou dat woordeboeke steeds voorkeurbronne vir die oplossing van bepaalde probleemtipes kan wees. Dit moet veral ook in ag geneem word dat ' $n$ wesenlike deel van die potensiële gebruikersgroepe van die toekoms tot ' $n$ nuwe geslag behoort, onder meer Generasie $Z$. Dit is lede van die samelewing wat na 2000 gebore is. 
Woordeboeke moet ook werktuie wees waarmee lede van Generasie Z inligting kan bekom wat aan hulle leksikografiese behoeftes voldoen. Hierdie generasie is digitale burgers wat die internet as vanselfsprekend aanvaar en alles daar wil vind — vergelyk Parker (2013), Finch (2015) en Gouws (2017). Dit het implikasies vir woordeboektipologie, die strukture van woordeboeke en die leksikografiese daarstelling van data. Finch (2015) sê:

It's critical that we recognize Gen Z's differences and meet them where they are, rather than where we want them to be.

Die ingrypende verskil tussen lede van die digitale maatskappy en die voorafgaande geslagte blyk ook daaruit dat hulle 'n ander benadering tot die naslaanaktiwiteit en naslaanwerke het. Hulle wil verkieslik 'n enkele instrument hê wat toegang tot alle data gee wat hulle nodig het; ook data wat tradisioneel in woordeboeke aangebied word.

Die aanpassing van die teoretiese leksikografie, die leksikografiepraktyk en daarom ook leksikografiese strukture by die digitale omgewing dwing metaleksikograwe en leksikograwe om steeds bedag te wees op die eise vanuit die gebruikersperspektief.

\section{Leksikografiese strukture en woordeboeknavorsing}

In verskeie van sy publikasies, onder meer Wiegand (1989: 262; 2010: 250) dui die metaleksikograaf Herbert Ernst Wiegand daarop dat die metaleksikografie, as afdeling van die breë terrein van woordeboeknavorsing, in vier hoofonderafdelings verdeel kan word. Hierdie afdelings is historiese woordeboeknavorsing, navorsing oor woordeboekkritiek, navorsing oor woordeboekgebruik en sistematiese woordeboeknavorsing. Volgens Wiegand (2010: 250) is die opdrag aan die sistematiese woordeboeknavorsing om op die basis van empiriese ondersoek 'n teorie van die leksikografiese proses te behandel en wel as deelteorie van 'n algemene leksikografieteorie. In die leksikografieseprosesteorie word drie deelteorieë onderskei, te wete 'n teorie van die behandeling van leksikografiese data, 'n teorie van draers van leksikografiese tekste en 'n teorie van woordeboekindeling (Wiegand 2010: 251).

Wiegand (2010: 251) dui ook aan dat in die teorie van die draers van leksikografiese tekste woordeboeke beskou word as teksdraers, dit wil sê hulle is opgebou uit verskillende soorte tekste. In hierdie verband is gedrukte woordeboeke statiese en digitale woordeboeke dinamiese inligtingstelsels. In die teorie van draers van leksikografiese tekste gaan dit onder meer om 'n deelteorie wat op die woordeboekvorm fokus as deel van 'n teorie oor die strukture van leksikografiese tekste en deeltekste.

Navorsing oor woordeboekstrukture is deeglik ingebed in ' $n$ algemene leksikografieteorie. Hierdie navorsing, en by name die uitgebreide en baanbrekerswerk wat Wiegand in hierdie verband gedoen het, is grootliks op gedrukte woordeboeke gerig. Wiegand stel dit in verskeie van sy publikasies 
eksplisiet dat dit op die strukture van gedrukte woordeboeke gerig is, vergelyk onder meer Wiegand (2005), Wiegand en Beer (2013), Wiegand, Feinauer en Gouws (2013), Wiegand en Gouws (2013, 2013a), Wiegand en Smit (2013; 2013a). Ook hierdie gebied van die metaleksikografie moet opnuut bekyk word met die oog op ' $n$ vasstelling van die strukture wat in aanlyn woordeboeke benut word. In hierdie verband moet aandag gegee word aan daardie strukture wat in sowel gedrukte as aanlynwoordeboeke voorkom maar bepaalde aanpassings in aanlyn woordeboeke vereis, maar ook aan die strukture wat slegs in óf gedrukte óf aanlyn woordeboeke voorkom. Vir aanlyn woordeboeke moet die bespreking van leksikografiese strukture gerig wees op hulle bydrae tot ' $n$ dinamiese inligtingstelsel. Bestaande bydraes in hierdie verband is onder meer Gouws (2014, 2014a, 2014b, 2018, 2018a, 2018b) asook Klosa en Gouws (2015).

Die tempo van die beskikbaarstelling van aanlyn woordeboeke en die aantal woordeboeke wat geproduseer is, staan in skrille kontras tot die trae ontwikkeling in metaleksikografiese beskouing van en teorievorming oor aanlyn woordeboeke. Dit blyk 'n herhaling te wees van die verhouding tussen teorie en praktyk in die ontwikkeling van gedrukte woordeboeke, vergelyk Gouws (2011), waar die praktyk die teorie voorafgegaan het in stede daarvan om die teorie te volg. Die snelheid waarteen leksikografies minder goeie aanlyn woordeboeke op die mark gekom het, stel tans hoë eise aan die metaleksikografie om modelle daar te stel wat 'n gehalteverbetering van aanlyn woordeboeke kan verseker en die leksikografiese behoeftes van 'n vinnig veranderende gebruikersmark op 'n doeltreffende manier kan bevredig.

Die ontwikkeling van die aanlyn leksikografiese praktyk het op verskillende maniere en in verskillende fases plaasgevind. Die vroeë ontwikkeling het tot produkte gelei wat oorspronklik as gedrukte woordeboeke gepubliseer is en toe, soms via die CD ROM-roete en soms nie, gedigitaliseer is en aanlyn beskikbaar gestel is. Na voorkoms was hierdie woordeboeke dikwels slegs gedigitaliseerde weergawes van gedrukte woordeboeke wat elektronies selfs nog deurgeblaai kon word. 'n Verdere ontwikkeling het dieselfde woordeboeke beter aangebied met toegangstrukture wat gebruikers vinniger op die verlangde soekroetes kon plaas en 'n aanbieding waarvan die artikels grootliks nog die vorm van dié van hulle gedrukte voorgangers weerspieël het, maar waar die tradisionele bladsybeeld en -uitleg ontbreek het. 'n Ander ontwikkeling het daartoe gelei dat woordeboeke van meet af as aanlyn woordeboeke saamgestel is met al die voordele van onder meer verbeterde soekmoontlikhede. Dit is die werklike aanlyn woordeboeke wat voortaan in hierdie bydrae ter sprake kom.

Alhoewel dit in veral hierdie laaste ontwikkeling dikwels duidelik was dat die nodige metaleksikografiese onderbou ontbreek, was dit vanuit 'n metaleksikografiese perspektief eweneens duidelik dat daar opnuut gekyk moet word na en leiding verstrek moet word oor die benutting van woordeboekstrukture. Vrae moet ook gestel word oor of die tradisionele leksikografiese strukture wat vir gedrukte woordeboeke ontwerp is ook ter sake is vir aanlyn woordeboeke. Daar moet ook voorsiening gemaak word vir nuwe strukture 
wat na vore tree. ' $n$ Besinning oor leksikografiese strukture as ' $n$ wesenlike deel van 'n algemene leksikografieteorie moet ook tot 'n besinning lei oor of die geldigheidsbestek van 'n algemene leksikografieteorie vir gedrukte woordeboeke ook aanlyn woordeboeke insluit. Dit benadruk weer die behoefte aan een algemene leksikografieteorie wat nie medium-spesifiek is nie.

\section{Aanpassing van leksikografiese strukture}

\subsection{Strukture wat reeds behandel is}

Daar is vroeër in hierdie artikel reeds verwys na bydraes soos Gouws (2014, 2014a, 2014b, 2018, 2018a, 2018b) asook Klosa en Gouws (2015) waarin die aanpassing van sekere leksikografiese strukture vir aanlyn woordeboeke ter sprake gebring is. In hierdie bydraes is die fokus veral op die makro-, artikel-, adresserings- en toegangstruktuur. Telkens word die belang van 'n voortsetting van die spesifieke struktuurtipe in aanlyn woordeboeke bevestig, maar telkens word daar ook gewys op aanpassings wat gemaak moet word en vernuwing wat danksy die aanlyn omgewing moontlik is.

In aanlyn woordeboeke bly die makrostruktuur 'n ordeningstruktuur, maar dit bied nie noodwendig meer aan gebruikers dieselfde soort oorsig oor die lemmaversameling van 'n bepaalde woordeboek nie. Deeltrajekte tree sterk op die voorgrond en die hooftoegangstruktuur val nie meer noodwendig saam met die makrostruktuur nie (Gouws 2014a). Aanlyn woordeboeke, Gouws (2014), het ' $n$ dinamiese en veelvlakkige artikelstruktuur wat dit vir gebruikers moontlik maak om doelgerig na spesifieke artikelsones te beweeg. Waar die adresseringstruktuur in gedrukte woordeboeke slegs ter sprake kom tussen individuele aanduiders en nooit in die geval van aanduidertekste nie, word daar voorgestel (Gouws 2015) dat aanduidertekste in aanlyn woordeboeke ook aan lemmatekens geadresseer kan word. Dit beklemtoon 'n wesenlike verskil tussen gedrukte en aanlyn woordeboeke wat spruit die aard van die verhoudings wat deur die adresseringstruktuur blootgelê word en die mindere mate van teksverdigting in aanlyn woordeboeke.

Alhoewel die toegangstruktuur in sowel gedrukte as aanlyn woordeboeke 'n belangrike rol speel, toon Gouws (2018a) aan hoe die aanlyn omgewing nuwe tipes toegangstrukture en toegangsroetes moontlik maak. Die toegangstruktuur in aanlyn woordeboeke is waarskynlik die struktuur wat die grootste en opvallendste verskille toon met die voorkoms van die ooreenstemmende struktuur in gedrukte woordeboeke. Die herwinning van inligting uit leksikografiese data hoef nie meer noodwendig via die lemmateken as gidselement van 'n artikel te wees nie. Die toegangstruktuur bied soekroetes wat kundige gebruikers regstreeks na bepaalde soeksones of spesifieke aanduiders kan lei.

In die res van hierdie artikel is die fokus veral op die dataverspreidingstruktuur en implikasies van die toepassing daarvan, onder meer die erkenning van 'n nuwe struktuurtipe. 


\subsection{Die dataverspreidingstruktuur}

\subsubsection{Buitetekste en die raamstruktuur}

Die dataverspreidingstruktuur is die struktuur wat die plasing en ordening van data in 'n woordeboek as draer van tekssoorte bepaal. Dit gaan nie net om die plasing van die lemmata en die artikelinterne aanduiders nie, maar ook om die plasing van buitetekste in die voor-, middel- en agtertekste-afdelings. Vir die dataverspreidingstruktuur in gedrukte woordeboeke bied die woordeboek se raamstruktuur aan leksikograwe die moontlikheid om verskillende plasingsomgewings vir die verskillende tekstipes te vind. 'n Raamstruktuur, vergelyk Kammerer en Wiegand (1998), is 'n tipe ordeningstruktuur wat nie ter sake is vir aanlyn woordeboeke nie. Alhoewel aanlyn woordeboeke ook tekste kan bevat wat in 'n gedrukte woordeboek as buitetekste beskou sou word, is hierdie tekste nie meer in vaste liniêre posisies tot die sentrale teks as voortekste, middeltekste en agtertekste geplaas nie. In aanlyn woordeboeke gaan dit ook nie noodwendig oor tekste wat die leksikografiese aanbod van die sentrale teks aanvul nie. Daar kan ook klank- of beeldgrepe wees asook grafika en ander tipes data-aanbod. Gevolglik stel Klosa en Gouws (2015) voor dat daar van buitekenmerke eerder as buitetekste gepraat moet word. In hierdie artikel sal die term buitekomponente eerder gebruik word vir daardie tekste of ander datahouers wat buite die grense van 'n woordeboek se alfabetiese komponent val. Die aard van ' $n$ aanlyn woordeboek oorskry dus die siening wat Wiegand (1996: 136) en Kammerer en Wiegand (1996: 224) ten opsigte van gedrukte woordeboeke voorstel, naamlik dat die woordeboek 'n draer van tekssoorte is. Aanlyn woordeboeke kan veel meer as tekste bevat.

Vir die doel van hierdie artikel is dit belangrik om daarop te let dat die aanlyn omgewing nie 'n raamstruktuur gebruik nie. Die buitetekste van gedrukte woordeboeke word in aanlyn woordeboeke as buitekomponente beskou wat nie ' $n$ vaste posisie met betrekking tot die alfabetiese komponent van die woordeboek het nie. Daar moet steeds onderskei kan word tussen aanlyn woordeboeke met en dié sonder buitekomponente. In hulle bespreking van die dataverspreidingstruktuur onderskei Bergenholtz, Tarp en Wiegand (1999: 1779) tussen ' $n$ eenvoudige dataverspreidingstruktuur en ' $n$ uitgebreide dataverspreidingstruktuur. Die eersgenoemde kom voor waar 'n woordeboek se leksikografiese data slegs in die sentrale teks aangebied word, terwyl die tweede tipe verwys na woordeboeke waar die sentrale teks aangevul word deur buitetekste wat ook as draers van leksikografiese data gebruik word. Hierdie onderskeid tussen die twee tipes dataverspreidingstruktuur is steeds vir die aanlyn omgewing bruikbaar en sal in hierdie artikel gebruik word.

Naas die uitgebreide dataverspreidingstruktuur maak die aanlyn omgewing ' $n$ verdere tipe dataverspreiding moontlik, naamlik die omvattende dataverspreidingstruktuur. 


\subsection{2 'n Omvattende dataverspreidingstruktuur}

Volgens Wiegand, Beer en Gouws (2013: 63) is 'n woordeboek as geheel 'n soekveld met elke artikel wat as soekgebied optree en uit 'n aantal soeksones bestaan waarin die verskillende aanduiders en merkers (vergelyk Wiegand en Smit 2013: 153) as funksionele tekssegmente geplaas word.

Die dataverspreidingstruktuur van aanlyn woordeboeke is uiteraard steeds grootliks daarop gerig om data in die onderskeie woordeboekartikels te plaas. Die dinamiese artikelstruktuur en nuwe toegangstrukture lei die gebruiker regstreeks na die tersaaklike soeksone. Naas die artikels tree bepaalde buitekomponente as plasingskandidate vir leksikografiese data op. Dié plasing word met behulp van die uitgebreide dataverspreidingstruktuur deurgevoer. In die aanlyn omgewing is die dataverspreiding nie tot die posisies in die artikels of dié in die buitekomponente beperk nie. Aanlyn woordeboeke tree nie altyd slegs as geïsoleerde naslaanbronne op nie, maar vorm soms deel van 'n woordeboekportaal. Dit lei tot die daarstelling van 'n nuwe struktuur, te wete die woordeboekportaalstruktuur. Hierdie struktuur het implikasies vir die dataverspreiding, vergelyk Gouws (2018b), en leksikograwe moet nogmaals aandag gee aan die bestek van die dataverspreidingstruktuur.

Engelberg en Müller-Spitzer (2013: 1024) gebruik die term woordeboekportaal om na ' $\mathrm{n}$ spesifieke tipe datastruktuur te verwys:

(i) that is presented as a page or set of interlinked pages on a computer screen and (ii) provides access to a set of electronic dictionaries, (iii) where these dictionaries can also be consulted as standalone products.

Engelberg en Müller-Spitzer (2013: 1027) onderskei drie verskillende tipes woordeboekportale, te wete 'n woordeboeknetwerk, 'n woordeboeksoekenjin en 'n woordeboekversameling. Woordeboekversamelings, volgens Engelberg en Müller-Spitzer (2013: 1028) die eenvoudigste tipe woordeboekportaal, is dikwels webbladsye met skakels na aanlyn woordeboeke maar die woordeboeke in 'n woordeboekportaal kan almal ook op die portaal se tuisblad verskyn. Vanuit 'n gebruikersperspektief is 'n woordeboekportaal 'n vertrekpunt vanwaar die gebruiker met behulp van verskillende soekroetes toegang kan kry tot verskillende woordeboeke en die leksikografiese data in daardie woordeboeke. Die gebruiker kan hom of haar tot slegs 'n enkele woordeboek wend of dieselfde data in meerdere woordeboeke in die portaal nagaan.

OWID, die Online Wortschatz Informationssystem Deutsch (aanlyn woordeskatinligtingstelsel van Duits) van die Institut für Deutsche Sprache bied die volgende openingsblad ter aanduiding van hulle woordeboekportaal - met ' $n$ aanduiding van die verskillende woordeboeke in die kolom aan die regterkant: 


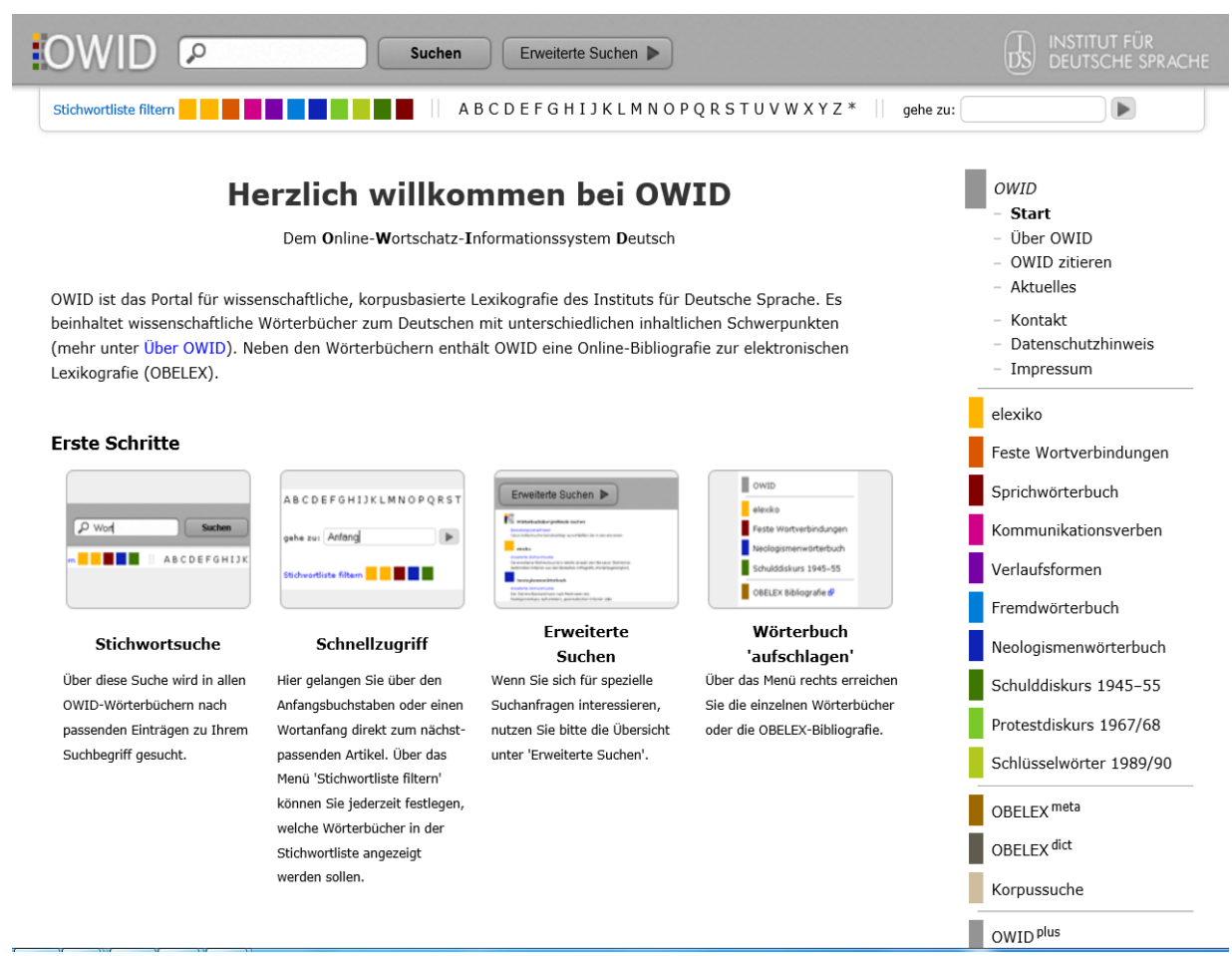

Afbeelding 1: Skermskoot uit OWID

In die beplanning van 'n woordeboekportaal moet daar vir die tradisionele dataverspreidingstruktuur van die indiwiduele woordeboeke voorsiening gemaak word asook vir die verspreiding van data in die portaal as sodanig. Dit geskied deur middel van 'n omvattende dataverspreidingstruktuur. In die beplanning van die portaal moet die leksikograaf vasstel watter woordeboeke in die portaal optree asook watter data in watter woordeboek aangebied moet word. Die toegangstruktuur moet dan so ontwerp word dat die gebruiker die relevante inskrywings in die onderskeie woordeboeke kan bereik. Elk van die woordeboeke in die woordeboekportaal kan ook 'n uitgebreide dataverspreidingstruktuur hê en gebruikers moet leiding kry oor watter data alles binne die portaal beskikbaar is.

\section{5. 'n Oorkoepelende datastruktuur}

\subsection{Woordeboek-eksterne bronne}

Die toetrede van woordeboekportale tot die aanlyn leksikografie noodsaak die inwerkingstelling van omvattende dataverspreidingstrukture aangesien die 
leksikografies relevante data oor verskillende bronne heen versprei kan word. Die mediostruktuur moet ook aangepas word want verwysings kan nou ook tussen verskillende woordeboeke in die woordeboekportaal gemaak word. Mediostruktuurtipes wat vir gedrukte woordeboeke ontwerp is, maak reeds voorsiening vir woordeboekeksterne kruisverwysingsadresse. Dit is die tipe mediostruktuur wat ook deel vorm van die kruisverwysingstelsel in 'n woordeboekportaal, waar die mediostruktuur aangepas moet word om nou ook 'n woordeboekeksterne maar portaalinterne kruisverwysingsadres te kan hê.

In én enkelwoordeboeke met óf 'n eenvoudige óf 'n uitgebreide dataverspreidingstruktuur én woordeboekportale met 'n omvattende dataverspreidingstruktuur geld dieselfde kernbenadering. Die leksikograaf besluit op data wat ter beskikking van die gebruiker gestel moet word en die dataverspreidingstruktuur as 'n ordenings- en plasingstruktuur bepaal die leksikografiese ruimte waar die data waaraan gebruikers inligting moet onttrek, geplaas moet word. Daardie leksikografiese ruimte kan verskillende woordeboeke wees en in hierdie woordeboeke hetsy soeksones binne die bepaalde soekveld se soekgebiede (vergelyk Wiegand, Beer en Gouws 2013: 63), hetsy buitekomponente wat onder meer tekste, grafika, beeld- of oudiodata kan wees.

Die vraag wat in 'n vernuwende benadering tot aanlyn leksikografie gevra kan word, is of die woordeboekeksterne bronne nie ook buite die woordeboekportaal kan val en gebruikers dus inligting kan onttrek aan bronne wat nie noodwendig leksikografiese bronne is nie. Leksikografiese strukture is noodsaaklik om sowel die voorkoms en aanbieding as die opsporing van en toegang tot inhoud te optimeer. 'n Algemene leksikografieteorie behoort dus ook aandag te gee aan die daarstelling van strukture wat op 'n nuwe manier die gebruiker kan help om ook woordeboekeksterne inligting te bekom. Aanlyn woordeboeke se inskakeling by 'n oorkoepelende datastruktuur kan tot nuwe vorme van datatoegang lei.

Vir die verstaan van strukture in aanlyn woordeboek is dit volgens Müller-Spitzer (2013: 369) noodsaaklik om nie net na die aanbiedingsvlak te kyk nie, maar ook na die databasisvlak. Atkins en Rundell (2008: 264) beskou 'n databasis as ' $n$ gestruktureerde versameling data op grond waarvan woordeboekartikels geskep kan word. Die leksikografiese databasis word gevul met data wat onder meer uit een of meer leksikografiese korpora kom en die samestelling van hierdie korpora en die vind van die gepaste data vir die databasis val binne die bestek van die woordeboekkonseptualiseringsplan wat dataversameling as een van sy onderafdelings het, vergelyk Wiegand (1998: 151). In gedrukte en tradisionele aanlyn woordeboeke strek die gebruiker se soektog na inhoud nie verder as die data wat vanuit 'n korpus in die databasis van die indiwiduele woordeboek of ' $n$ ander woordeboek in die betrokke woordeboekportaal neerslag gevind het nie. Die bestaande leksikografiese strukture laat nie verdere soektogte toe nie.

In die benutting van leksikografiese korpora, die saamstel van die databasis en die ontrekking van data aan die databasis om as aanduiders in woordeboekartikels of inskrywings in buitekomponente te dien, speel die leksiko- 
graaf die bepalende rol. Die leksikograaf maak naamlik die keuse, weliswaar gebaseer op die vasgestelde behoeftes van 'n geïdentifiseerde teikengebruiker. In gedrukte woordeboeke is daar 'n vaste en statiese verhouding tussen gebruiker en leksikograaf met 'n eenrigtingverskaffing van data. Die gebruiker word met die data gekonfronteer wat die leksikograaf aanbied en het geen moontlikheid om alternatiewe data in die betrokke woordeboek te vind nie; al het die gebruiker in sommige aanlyn woordeboeke die geleentheid om regstreeks toegang te kry tot slegs sekere buitetekste of soeksones in 'n bepaalde artikel. Vir woordeboeke in die dinamiese aanlyn omgewing word 'n vergelykbare verhouding gehandhaaf van die leksikograaf wat die verskaffer van data is deur keuses uit ' $n$ korpus te maak en met behulp van 'n spesifieke databasisprogram die data 'n neerslagplek in woordeboekartikels of in buitekomponente te laat vind. Die moontlikheid bestaan wel om aan een databasis verskillende woordeboeke te onttrek — vergelyk Bergenholtz en Bothma (2011: 64).

'n Oorsig oor strukture op sowel die aanbiedings- as die databasisvlak van aanlyn woordeboeke bevestig steeds die eenrigtingverhouding tussen leksikograaf en gebruiker; al het die gebruiker soms die moontlikheid om keuses te maak van wat hy of sy wil sien of nie wil sien nie.

\subsection{Stoot- en trekbenaderings in kommunikasie}

Müller-Spitzer (2013: 369) verwys na die onderskeid tussen 'n trekmedium en 'n stootmedium met onder meer boeke, radio en televisie wat tot die stootmedium behoort en die internet wat sy as 'n trekmedium beskou. Sy meld dat die internet 'n nuwe vorm van kommunikasie bied wat 'n vernuwende kombinasie van nuwe media is. Hierdie kenmerk van die internet het volgens MüllerSpitzer gevolge vir aanlyn woordeboeke as 'n tipe internetteks.

Dit is ter sake om hier kortliks iets oor die terme trekmedium en stootmedium te sê. In die inligtingswetenskap en rekenaarwetenskap word die stootmedium gesien as 'n medium waar die sender die identiteit van die ontvanger ken en data voorsien wat deur die ontvanger ontvang en dan aanvaar word al dan nie. Die volledige boodskap word deur die ontvanger ontvang voordat die ontvanger met die verwerking daarvan kan begin — vergelyk Duan et al. (s.j.). Die sender beheer watter boodskap gelewer moet word en ook wanneer dit gelewer moet word. Die ontvanger weet nie watter boodskap ontvang gaan word nie.

Volgens Duan et al. (s.j.) word die oordrag van 'n boodskap in 'n trekmedium deur die ontvanger in werking gestel deurdat die ontvanger dit van die sender vra. Die sender lewer die verlangde inligting wanneer dit gevra word deur die ontvanger. Hulle beweer dat die ontvanger in so 'n medium groter beheer oor die oordrag van die boodskap het en meer vertroue stel in die inhoud wat ontvang word in vergelyking met die stootmodel. Belangrik is dat die ontvanger die keuse het om sy/haar vlak van belang in die inhoud (asook die reputasie van die sender) te bepaal alvorens die spesifieke inhoud aangevra word. Dit is die sender se verantwoordelikheid om die data te berg en te beheer totdat die ontvanger gereed is om dit aan te vra. 
Duan et al. (s.j.) beweer dat die een nadeel van ' $n$ trekbenadering is dat die sender belas word met meer bestuur van die inhoud, maar die voordeel is dat dit die probleem van ongevraagde data-oordrag verminder.

Vanuit die perspektief van die ontvanger verg die stootmodel 'n passiewe en die trekmodel 'n aktiewe benadering tot dataverkryging.

Volgens Deolasee et al. (s.j.) het die trekgebaseerde benadering nie noodwendig altyd hoë betroubaarheid nie want die data verander vinnig. 'n Stootgebaseerde benadering het groter betroubaarheid ten opsigte van vinnig veranderende data, maar dit gebruik veel meer plek en is makliker aan mislukking blootgestel.

Vir die doel van hierdie artikel is die wesenlike onderskeid tussen die stoot- en die trekmedium dat in die stootbenadering in netwerkkommunikasie die sender besluit watter data voorsien moet word, terwyl in die trekbenadering die versoek om data van die ontvanger kom en dat hierdie data dan deur die sender voorsien word.

Die interdissiplinêre aard van die leksikografie noodsaak dit dat daar in die teorie-ontwerp asook in die praktyk ruim aandag gegee moet word aan ontwikkelinge in verwante dissiplines, onder meer die inligtingswetenskap. Die gerigtheid op die behoeftes van die gebruiker maar ook die teikengebruikersgroep se naslaanvaardighede en naslaanomgewingsvoorkeure moet eweneens bepalend wees in die ontwikkeling van die aanlyn leksikografie.

Alhoewel die stoot- en trekbenaderings nie vir die leksikografie ontwerp is nie en ook nie sonder meer daarop van toepassing gemaak kan word nie, is daar wel sekere grondliggende aspekte van hierdie benaderings wat leksikografies waardevol en prakties bruikbaar kan wees. Na analogie van hierdie benadering in die inligtingswetenskap en rekenaarwetenskap waar verskillende media in terme van ' $n$ trek- al dan stootbenadering geklassifiseer kan word, kan daar in die leksikografie beweer word dat gedrukte woordeboeke asook tradisionele aanlyn woordeboeke grootliks binne die stootmedium val. Die leksikograaf, as sender, voorsien naamlik die data en die gebruiker, as ontvanger, het geen seggenskap oor die aard en omvang van die data wat beskikbaar gestel word nie. Selfs waar verskillende tipes data aan een databasis onttrek word volgens die profiel van die gebruiker, vergelyk Bergenholtz en Bothma (2011: 63), is die inligting wat die gebruiker uiteindelik ontvang 'n onttrekking aan data waarop die leksikograaf besluit het.

\subsection{Ten gunste van 'n datatrekkingstruktuur as deel van 'n oorkoepelende datastruktuur}

Rundell (2016: 11) sê:

The Web and social media have created conditions which have overturned the older, top-down media model, where a small number of providers (whether journalists or lexicographers) delivered expertly-curated content to a large number of consumers. Consumers were for the most part passive: a handful of "Let- 
ters to the Editor" of a newspaper (or of a dictionary) represented the limits of user-participation. In the new paradigm, ordinary individuals can make a contribution, and increasingly expect to do so.

Hierdie opmerking van Rundell sluit aan by sy betoog oor die groter betrokkenheid van woordeboekgebruikers by die saamstel van woordeboeke en die benutting van skarehulp ("crowdsourcing") in die daarstelling van gebruikergeskepte inhoud. Groter betrokkenheid van gebruikers kan egter ook bereik word deur aan hulle die geleentheid te bied om inligting aan woordeboekeksterne bronne te onttrek, veral waar hierdie bronne nie deel van 'n woordeboekportaal is nie en dus nie deel van data wat die leksikograaf vir 'n spesifieke naslaanprosedure vanuit ' $n$ datastootbenadering gelewer het nie. Teenoor die benadering om ' $n$ woordeboek as 'n stootmedium te beskou met die gepaardgaande situasie dat die leksikograaf as sender volledige beheer het oor die data wat aangebied word, vergelyk Duan et al. (s.j.), kan 'n benadering waar aanlyn woordeboeke aangepas word om 'n trekbenadering te hê tot 'n veel groter en aktiewer deelname van gebruikers aan die materiaalversamelingsfase van die leksikografiese proses en die onttrekking van inligting ter bevrediging van indiwiduele gebruikersbehoeftes lei.

Met verwysing na die stoot- en trekbenaderings in netwerkkommunikasie sê Müller-Spitzer (2013: 369) oor woordeboekgebruikers:

Therefore, users are both sender and receiver. They are active in 'pulling' data from the website, saving relevant parts, etc. Thus, the Internet provides a very new form of communication in general. It is communication in an innovative combination with new media.

En dan ook:

The process of pulling and, thus, representing lexicographic data according to a user request is essential for EDs (electronic dictionaries - RHG) and must be considered when the textual structures of EDs are being looked at.

Die skep van 'n leksikografiese datatrekkingstruktuur kan aanlyn woordeboeke binne die bestek van 'n oorkoepelende datastruktuur plaas waar gebruikers inligting aan 'n verskeidenheid woordeboekeksterne bronne kan onttrek. Die leksikograaf as primêre sender het steeds die besluit oor watter bronne beskikbaargestel word, maar het nie beheer oor die inligting wat gebruikers aan die data in hierdie bronne onttrek nie.

'n Leksikografiese datatrekkingstruktuur kan gesien word as 'n struktuur met 'n reeks geordende elemente om die stappe daar te stel wat ' $n$ woordeboekgebruiker kan volg om vanuit ' $n$ gegewe posisie in ' $n$ bestaande aanlyn woordeboek (waar hierdie posisie óf 'n aanduider of soeksone in 'n woordeboekartikel of ' $n$ artikeleksterne posisie, byvoorbeeld 'n inskrywing in 'n buitekomponent, kan wees) toegang te kry tot woordeboekeksterne bronne waaraan die gebruiker inligting kan onttrek ter bevrediging van 'n bepaalde leksikografiese behoefte. 


\section{Bronne wat teikens van 'n datatrekkingstruktuur kan wees}

\subsection{Bestaande gebruike van die internet as korpus}

Gouws en Tarp (2017: 391) voer aan:

Today we are in the middle of a new transition of the material and technological basis of lexicography with the introduction of new production tools and methods as well as new platforms and media for presenting the lexicographic product and the extensive use of corpora for the collection of material. The development and technological innovation are going faster than ever before. (...) We know the point of departure but we still only have a vague idea of where we will eventually arrive.

Die veranderende verhouding tussen leksikografie en tegnologie het ' $n$ invloed op talle aspekte van die leksikografie en die leksikografiese proses; ook op die benutting van korpora. Ook die omvang van die toekomstige gebruik van leksikografiese korpora sal aangepas word. In sy bespreking van korpora noem Fuertes-Olivera (2012: 51) onder meer dat 'n leksikografiese korpus 'n versameling tekste is. Tarp en Fuertes-Olivera (2016: 277) noem dat die internet ook 'n versameling tekste is en ook as 'n tipe leksikografiese korpus beskou kan word. Leksikograwe vul reeds die gebruik van tradisionele korpora aan deur die internet as korpus te gebruik vir die vind van 'n verskeidenheid datatipes, vergelyk onder meer Tarp en Fuertes-Olivera (2016). Die leksikograaf is steeds die voorsiener van tersaaklike data en hierdie data word deur die leksikograaf gekies en as aanduiders in die woordeboek verstrek - dikwels met erkenning aan die internetbron waaraan die data onttrek is. Vergelyk in hierdie verband afbeelding 2 - die aanlyn woordeboek elexico se illustrasieprente wat foto's is wat op die internet gevind is. In hierdie geval is dit aan die gratis prentedatabank pixelio.de onttrek en hierdie bron word deur die leksikograaf erken.

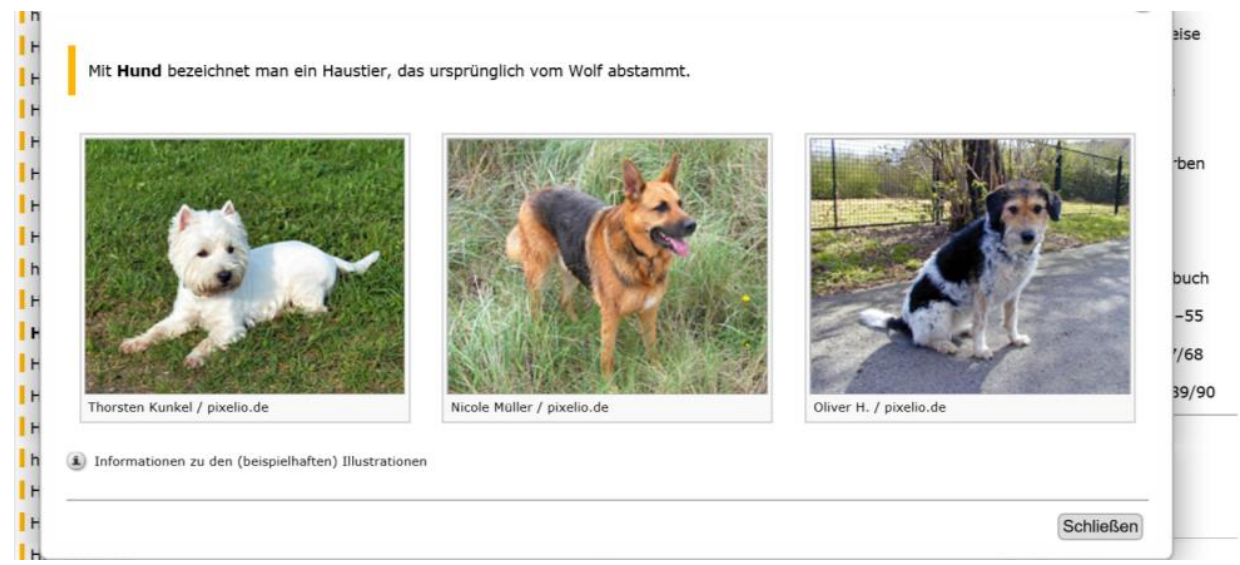

Afbeelding 2: Skermskoot uit elexico 
Tarp en Fuertes-Olivera (2016: 277) dui ook aan dat die internet as korpus op twee maniere deur die leksikograaf gebruik kan word. 'n Korpus kan naamlik saamgestel word uit tekste wat op die internet gevind is of die leksikograaf kan die internet regstreeks as korpus gebruik en data daaraan onttrek in 'n spesifieke leksikografiese bewerking. Die gebruiker het egter steeds geen sê in watter data uit die internet gebruik moet word nie; die aanlyn leksikografie bly ' $n$ stootmedium.

Daar is ' $\mathrm{n}$ ander tipe interaktiewe verhouding tussen woordeboek en teks waar daar van 'n bepaalde teks na 'n ingeboude woordeboek beweeg kan word, soos in die geval van Amazon se Kindle e-boeke. Deur 'n woord in die Kindle-boek uit te lig, word die gebruiker outomaties na 'n geskakelde e-woordeboek herlei waar die gebruiker die betekenis van die uitgeligte woord kan kry sonder om die boek wat hulle lees te verlaat. Kindle bied tans die moontlikheid om vanuit die opskietvenster wat op enige bladsy van die boek verskyn toegang te kry tot sy eie woordeboek en, indien die leser meer hulp benodig, ook toegang tot Google te kry. Na aanleiding hiervan moet die moontlikheid in meer besonderhede vir die leksikografie ondersoek word oor hoe om die gebruiker van aanlyn woordeboeke regstreeks met 'n Google-soektog te verbind wat dan toegang tot die internet as databron verskaf. Dit bied ruim geleentheid vir verdere navorsing.

Hedendaagse tegnologie maak dit moontlik om met uitgebreide en verfynde soekmetodes spesifiek daardie data in 'n woordeboek te vind wat die gebruiker nodig het, vergelyk Bothma en Prinsloo (2013: 168). Dit sluit aan by Tarp (2009: 29) se siening van dinamiese data in woordeboekartikels wat uniek is vir elke soekprosedure volgens die spesifieke gebruiker en gebruiksituasie. 'n Verdere moontlikheid wat vir die leksikografie nog in meer besonderhede ondersoek moet word, is om die gebruiker regstreeks met 'n Google-soektog te verbind wat toegang tot die internet as databron verskaf.

\subsection{Leksikografiese datatrekkingstrukture en 'n nuwe gebruik van die internet as korpus}

Woordeboeke lê op die kontinuum van inligtingsbronne en die benutting van 'n aanlyn woordeboek moet 'n sikliese aard hê wat sowel stoot- as trekmoontlikhede aan die gebruikers bied. Die benutting van 'n datatrekkingstruktuur in aanlyn woordeboeke bied aan gebruikers die geleentheid om vanuit 'n bepaalde punt in die woordeboek 'n eksterne bron te raadpleeg om bykomende inligting. Leksikograwe kan byvoorbeeld 'n aanlyn woordeboek koppel aan 'n bron soos Wikipedia en die gebruiker wat op soek is na bykomende hulp ter bevrediging van 'n kognitiewe funksie kan vanuit die aanlyn woordeboek na Wikipedia gelei word en daar die bykomende inligting vind. ' $n$ Klik op enige lemmateken in die aanlyn woordeboek kan die nodige skakel bied om data elders te gaan vind. Dit is 'n gedeeltelike trekbenadering want alhoewel die gebruiker kies waar hy/sy hulp nodig en alhoewel die leksikograaf nie weet 
watter data die gebruiker aan die woordeboekeksterne bron gaan onttrek nie, is die bron steeds deur die leksikograaf gekies en die data deur 'n stootbenadering tot die gebruiker se beskikking gestel.

' $n$ Ware datatrekkingbenadering kom voor waar die internet as geheel deel van 'n aanlyn woordeboek se datastruktuur en die teiken van 'n datatrekkingstruktuur se toepassing is. Die tegniese aspekte hiervan word nie in hierdie artikel bespreek nie, maar die ideaal van 'n volwaardige datatrekkingstruktuur word voorgehou. Dit vereis 'n wisselwerking tussen die data wat woordeboekintern aangebied word, die databasis van die woordeboek en die internet as woordeboekeksterne bron, 'n buitekomponent in eie reg.

Wanneer enige aanduider in ' $n$ woordeboekartikel uitgelig word, verskyn daar 'n klein opskietspyskaart met 'n lysie datatipes wat die gebruiker mag nodig hê, byvoorbeeld koteksinskrywings, waaronder voorbeeldsinne en kollokasies, uitvoeriger betekenisparafrases, etimologiese inligting, uitspraakinligting, konteksinligting, ensovoorts. Dit is weliswaar datatipes wat die leksikograaf kies, maar oor die inhoud van die kategorieë het die leksikograaf geen seggenskap nie. Deur op 'n spesifieke spyskaartitem te klik, word die gebruiker deur 'n soekroete wat deur die datatrekkingstruktuur bepaal word na 'n teks in die internet gelei waar die nodige databystand verkry kan word. Dit vereis dat die databasis van die woordeboek op so 'n manier saamgestel word dat die gebruiker via die klik van 'n spyskaartitem in die regte rigting na die internet gestuur word. Deur die stel geordende fases van die datatrekkingstruktuur kan 'n woordeboekgebruiker toegang tot 'n veel wyer data-aanbod kry as wat die woordeboekinterne dataverspreidingstruktuur kan voorsien.

Die datatrekkingstruktuur wat die internet as teiken het, verander die aard van die betrokke aanlyn woordeboek as netwerkinstrument en maak daarvan 'n geïntegreerde inligtingswerktuig. Die woordeboekgebruiker word 'n aktiewe deelnemer wat besluitnemingsmag het oor die data waarna hy/sy wil soek as deel van die uitvoering van 'n voortgaande leksikografiese proses. So 'n proses lei tot 'n ander perspektief op die gesag van woordeboeke. Die leksikograaf het geen beheer oor die aard van die data wat die gebruiker aan die internet onttrek nie. Die gebruiker dra die verantwoordelikheid daarvoor om die gehalte van hierdie data te beoordeel.

\section{Ten slotte}

Metaleksikografiese navorsing moet aandag gee aan voorstelle vir die aanpassing van leksikografiese strukture om die aanlyn omgewing optimaal te kan benut. In hierdie verband is interdissiplinêre samewerking nodig; ook om seker te maak dat die voorstelle van metaleksikograwe tegnies uitvoerbaar is. Die idee van 'n datatrekkingmedium is reeds gevestig in die inligtings- en rekenaarwetenskap. Leksikograwe moet samewerking gee om 'n datatrekkingbenadering in aanlyn woordeboeke moontlik te maak.

Die daarstelling van ' $n$ geordende stel opeenvolgende stappe wat ' $n$ data- 
trekkingstruktuur kan skep en die toepassing daarvan kan aan woordeboekgebruikers 'n aktiewe deelname bied om nie net leksikografiese data vir die leksikograaf te voorsien soos in die geval van skarehulp nie, maar om self data uit die internet as leksikografiese data te ontgin en wel op ' $n$ manier wat aan spesifieke behoeftes van spesifieke gebruikers in spesifieke gebruiksituasies voldoen. So 'n trekbenadering sal ook help verseker dat 'n aanlyn woordeboek nie gebuk gaan onder die las van data-oorlading nie (vergelyk Gouws en Tarp 2017).

'n Datatrekkingstruktuur bring ook mee dat McArthur (1986) se siening van woordeboeke as "houers van kennis" minder relevant raak, aangesien die kennis oor verskillende houers — nie net woordeboeke nie — versprei word.

\section{Acknowledgement}

This work is based on the research supported in part by the National Research Foundation of South Africa (Grant specific unique reference number (UID) 85434). The Grantholder acknowledges that opinions, findings and conclusions or recommendations expressed in any publication generated by the NRF supported research are that of the author(s), and that the NRF accepts no liability whatsoever in this regard.

\section{Bronnelys}

Atkins, Beryl T.S. en Michael Rundell. 2008. The Oxford Guide to Practical Lexicography. Oxford/ New York: Oxford University Press.

Bergenholtz, Henning en Theo J.D. Bothma. 2011. Needs-adapted Data Presentation in e-Information Tools. Lexikos 21: 53-77.

Bergenholtz, Henning, Sven Tarp en Herbert Ernst Wiegand. 1999. Datendistributionsstrukturen, Makro- und Mikrostrukturen in neueren Fachwörterbüchern. Hoffmann, Lothar et al. (Reds.). 1999. Fachsprachen. Ein internationales Handbuch zur Fachsprachenforschung und Terminologiewissenschaft/Languages for Special Purposes. An International Handbook of Special-Language and Terminology Research, Bd./Vol. 2: 1762-1832. Berlyn: Walter de Gruyter.

Bothma, Theo J.D. en Daniel J. Prinsloo. 2013. Automated Dictionary Consultation for Text Reception: A Critical Evaluation of Lexicographic Guidance in Linked Kindle e-Dictionaries. Lexicographica 29: 165-198.

Deolasee, Pavan et al. s.j. Adaptive Push-Pull: Disseminating Dynamic Web Data. http://www-ccs.cs. umass.edu/ krithi/web/WWW10/www10/ (Geraadpleeg op 10 Mei 2018).

Duan, Zhenhai, Kartik Gopalan en Yingfei Dong. s.j. Push vs. Pull: Implications of Protocol Design on Controlling Unwanted Traffic. https://pdfs.semanticscholar.org/6f63/d37b4f8dd 655e3594185e74daf4689f55aa1.pdf (Geraadpleeg op 10 Mei 2018).

elexico: Online Wörterbuch zur deutschen Gegenwartssprache. Saamgestel deur die Institut für Deutsche Sprache, Mannheim. http://www.owid.de/wb/elexiko/start.html.

Engelberg, Stefan en Carolin Müller-Spitzer. 2013. Dictionary Portals. Gouws, Rufus H. et al. (Reds). 2013: 1023-1035. 
Finch, Jeremy. 2015. What Is Generation Z, And What Does It Want? http://www.fastcoexist.com/ 3045317/what-is-generation-z-and-what-does-it-want (Geraadpleeg op 28 Mei 2015).

Fuertes-Olivera, Pedro A. 2012. Lexicography and the Internet as a (Re-)source. Lexicographica 28: 49-70.

Gouws, Rufus H. 2011. Learning, Unlearning and Innovation in the Planning of Electronic Dictionaries. Fuertes-Olivera, Pedro A. en Henning Bergenholtz (Reds.). 2011. e-Lexicography: The Internet, Digital Initiatives and Lexicography: 17-29. Londen/New York: Continuum.

Gouws, Rufus H. 2014. Article Structures: Moving from Printed to e-Dictionaries. Lexikos 24: 155-177.

Gouws, Rufus H. 2014a. Makrostruktuuraanpassings vanaf gedrukte na e-woordeboeke. Tydskrif vir Geesteswetenskappe 54(3): 481-504.

Gouws, Rufus H. 2014b. Expanding the Notion of Addressing Relations. Lexicography: 1(2): 159-184.

Gouws, Rufus H. 2017. La sociedad digital y los diccionarios. Domínguez Vázquez, María José en María Teresa Sanmarco Bande (Reds.). 2017. Lexicografía y didáctica: 17-34. Frankfurt: Peter Lang.

Gouws, Rufus H. 2018. Dictionaries and Access. Fuertes-Olivera, Pedro A. (Red.). 2018. The Routledge Handbook of Lexicography: 43-58. Londen: Routledge.

Gouws, Rufus H. 2018a. Accessibility, Access Structures and Access Procedures. Jesenšek, Vida en Milka Enčeva (Reds.). 2018. Wörterbuchstrukturen zwischen Theorie und Praxis: 35-56. Berlyn: De Gruyter.

Gouws, Rufus H. 2018b. Internet Lexicography in the 21st Century. Engelberg, Stefan et al. (Reds.). Wortschatz: Theorie, Empirie, Dokumentation: 215-236. Berlyn: De Gruyter.

Gouws, Rufus H. et al. (Reds.). 2013. Dictionaries. An International Encyclopedia of Lexicography. Supplementary Volume: Recent Developments with Focus on Electronic and Computational Lexicography. Berlyn/New York: De Gruyter.

Gouws, Rufus H. en Sven Tarp. 2017. Information Overload and Data Overload in Lexicography. International Journal of Lexicography 30(4): 389-415.

Hartmann, Reinhard R.K. 1989. Sociology of the Dictionary User: Hypotheses and Empirical Studies. Hausmann, Franz J. et al. (Reds.). 1989-1991: 102-111.

Hartmann, Reinhard R.K. 2001. Teaching and Researching Lexicography. Londen: Pearson Education.

Hausmann, Franz J. et al. (Reds.). 1998-1991. Wörterbücher. Dictionaries. Dictionnaires. An International Encyclopedia of Lexicography. Berlyn: De Gruyter.

Kammerer, Matthias en Herbert Ernst Wiegand. 1998: Über die textuelle Rahmenstruktur von Printwörterbüchern. Präzisierungen und weiterführende Überlegungen. Lexicographica 14: 224-238.

Klosa, Annette en Rufus H. Gouws. 2015. Outer Features in e-Dictionaries. Lexicographica 31: 142-172.

McArthur, Tom. 1986. Worlds of Reference: Lexicography, Learning, and Language from the Clay Tablet to the Computer. Cambridge: Cambridge University Press.

Müller-Spitzer, Carolin. 2013. Textual Structures in Electronic Dictionaries. Gouws, Rufus H. et al. (Reds.). 2013: 367-381.

Parker, Phil. 2013. http://www.sec-ed.co.uk/blog/how-generation-z-is-different (Geraadpleeg Mei 2015).

Rundell, Michael. 2012. 'It Works in Practice but Will it Work in Theory?' The Uneasy Relationship between Lexicography and Matters Theoretical. Vatvedt Fjeld, R. en J. Matilde Torjusen (Reds.). 
2012. Proceedings of the 15th EURALEX International Congress, 7-11 August 2012, Oslo: 47-92. Oslo: Departement Linguistiek en Skandinawiese Studies, Universiteit van Oslo.

Rundell, Michael. 2016. (Ongepubliseer.) Dictionaries and Crowdsourcing, Wikis and User-generated Content.

Tarp, Sven. 2009. Beyond Lexicography: New Visions and Challenges in the Information Age. Bergenholtz, Henning, Sandro Nielsen en Sven Tarp (Reds.). 2009. Lexicography at a Crossroads: Dictionaries and Encyclopedias Today, Lexicographical Tools Tomorrow: 17-32. Frankfurt: Peter Lang.

Tarp, Sven en Pedro A. Fuertes-Olivera. 2016. Advantages and Disadvantages in the Use of Internet as a Corpus: The Case of the Online Dictionaries of Spanish Valladolid-UVa. Lexikos 26: 273-295.

Wiegand, Herbert Ernst. 1977. Nachdenken über Wörterbücher: Aktuelle Probleme. Drosdowski, Günther, Helmut Henne en Herbert Ernst Wiegand (Reds.). 1977. Nachdenken über Wörterbücher: 51-102. Mannheim/Wenen/Zürich: Bibliographisches Institut.

Wiegand, Herbert Ernst. 1989. Der gegenwärtige Status der Lexikographie und ihr Verhältnis zu anderen Disziplinen. Hausmann, Franz J. et al. (Reds.). 1989-1991: 246-280.

Wiegand, Herbert Ernst. 1996. A Theory of Lexicographic Texts. An Overview. SA Journal of Linguistics 14(4): 134-149.

Wiegand, Herbert Ernst. 1998. Wörterbuchforschung. Untersuchungen zur Wörterbuchbenutzung, zur Theorie, Geschichte, Kritik und Automatisierung der Lexikographie. Berlyn/New York: De Gruyter.

Wiegand, Herbert Ernst. 2005. Über die Datenakzessivität in Printwörterbüchern. Einblicke in neuere Entwicklungen einer Theorie der Wörterbuchform. Lexikos 15: 196-230.

Wiegand, Herbert Ernst. 2010. Zur Methodologie der Systematischen Wörterbuchforschung: Ausgewählte Untersuchungs- und Darstellungsmethoden für die Wörterbuchform. Lexicographica 26: 249-330.

Wiegand, Herbert Ernst en Sandra Beer. 2013. Textual Architectures in Printed Dictionaries. Gouws, Rufus H. et al. (Reds.). 2013: 253-273.

Wiegand, Herbert Ernst, Sandra Beer en Rufus H. Gouws. 2013. Textual Structures in Printed Dictionaries. An Overview. Gouws, Rufus H. et al. (Reds.). 2013: 31-73.

Wiegand, Herbert Ernst, Ilse Feinauer en Rufus H. Gouws. 2013. Types of Dictionary Articles in Printed Dictionaries. Gouws, Rufus H. et al. (Reds.). 2013: 314-366.

Wiegand, Herbert Ernst en Rufus H. Gouws. 2013. Macrostructures in Printed Dictionaries. Gouws, Rufus H. et al. (Reds.). 2013: 73-110.

Wiegand, Herbert Ernst en Rufus H. Gouws. 2013a. Addressing and Addressing Structures in Printed Dictionaries. Gouws, Rufus H. et al. (Reds.). 2013: 273-314.

Wiegand, Herbert Ernst en Maria Smit. 2013. Microstructures in Printed Dictionaries. Gouws, Rufus H. et al. (Reds.). 2013: 149-214.

Wiegand, Herbert Ernst en Maria Smit. 2013a. Mediostructures in Printed Dictionaries. Gouws, Rufus H. et al. (Reds.). 2013: 214-253. 